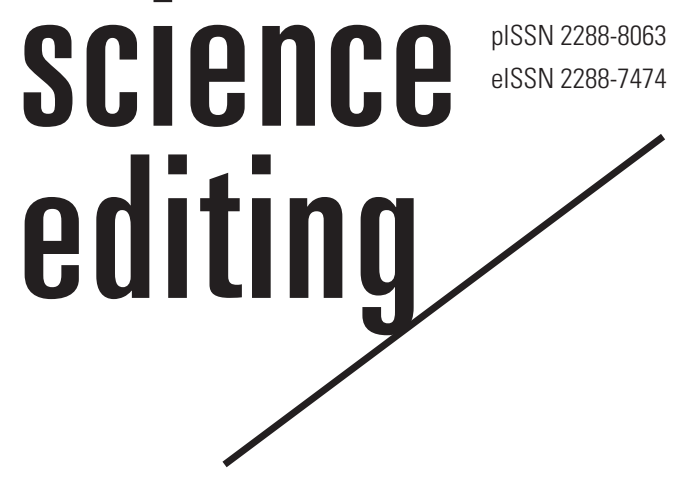

\title{
PKP 2017 International Scholarly Publishing Conference
}

\author{
Youngim Jung \\ Korea Institute of Science and Technology Information, Daejeon, Korea
}

The Public Knowledge Project (PKP) is a research and development initiative of Simon Fraser University (SFU) and Stanford University, with a focus on understanding and building enhanced modes of scholarly communication that facilitate open access, high-quality publishing, and local capacity building and participation [1]. The PKP has developed a series of free, open source software, such as Open Journal Systems (OJS), Open Monograph Press, Open Conference Systems, and Open Harvester Systems. The PKP has held biennial conferences since 2007 to provide an open forum to PKP community members and anyone interested in scholarly publishing.

The 6th PKP International Scholarly Publishing Conference was held at Université de Montréal, Quebec on August 2 to 4, 2017. The theme of this year's conference was "Reclaiming scholarship: voice, rights, ownership." The conference program consisted of 3 parts: technical sessions including PKP Sprints and the PKP Workshop; a 2-day symposium including invited speakers, lightning talks, and panel presentations; and social meet-ups for networking.

The first day of the conference commenced with the PKP Sprints. PKP Sprints are shortterm and ad-hoc events in which a group of programmers, editors, librarians, users, and others gather together once or twice a year to identify tasks, make priorities, and find solutions. A 2-day development sprint took place in conjunction with the PKP conference this year. Various tasks were discussed, with topics including "New user mediation," "Open typesetting stack," "Documentation update and architecture," "Upgrading OJS XML import/export," "Internal statistics," "Book sprint," "REST API," and "Making metadata fields required." Most suggestions and issues were recorded by the group leader, and on- and off-line communication was parallelized by utilizing Slack-a real-time communication and file exchange application for teams-during the brainstorming.

I joined the "Open typesetting stack" group to enhance my understanding and to help im-

Received: January 4, 2018 Accepted: January 8, 2018

Correspondence to Youngim Jung acorn@kisti.re.kr

ORCID

Youngim Jung

http://orcid.org/0000-0001-7924-6967 prove the user experience in languages other than English. The group was led by Alex Garnett, a Digital Preservation and Data Curation specialist at Simon Fraser University and one of the PKP staff members. The Open Typesetting Stack (OTS) refers to a standalone service for converting Microsoft word and PDF documents to structured National Library of Medicine Journal Article Tag Suite (JATS) XML and creating HTML, PDF, and ePub article views from the XML. We installed a beta version of the service and reviewed the design, the functions, and the workflow of the OTS plugin for OJS 3. The OTS Sprint leader assessed the discussion as being 


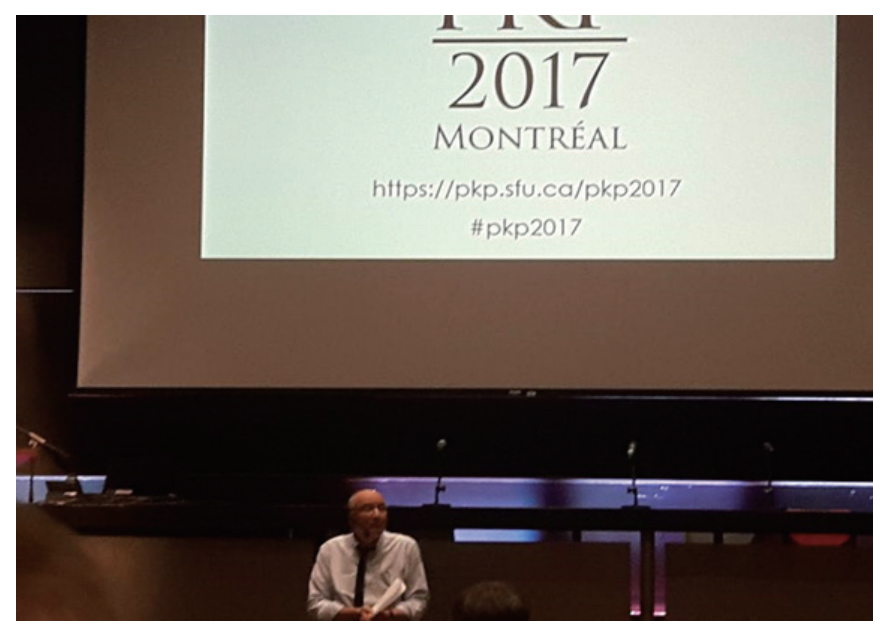

Fig. 1. Keynote speech addressed by John Willinsky.

highly useful and valuable because there were attendees who had not had much of an opportunity to experience OJS 3 previously, so that he was able to determine where their current assumptions regarding the plugin design did not make sense for novice users, and which aspects they liked. However, OTS does not work very well at the moment for non-Latin languages such as Korean, Chinese, and Japanese. If OTS is to be considered as a tool for Korean scholarly publishing and JATS XML creation, language issues in OTS-and even in OJSshould be solved first.

The second day of the conference featured a double track of the continuing Sprints and the PKP Workshop. The workshop was designed (1) to provide an overview of the current and upcoming characteristics of OJS 3, (2) to discuss what works well and what might be missing in the new release, and (3) to review the major considerations related to the decision of migrating from OJS 2 to OJS 3 and the necessary steps to complete the migration. Other questions and comments on working with OJS were freely discussed during the workshop.

In the afternoon, a single track of invited speakers, lightning talks, and a panel presentation followed the official welcome from Université de Montréal and Simon Fraser University. The opening address was made by John Willinsky, a professor at Stanford University and the founder and director of the PKP (Fig. 1). He addressed license and copyright issues, which were thrown into sharp focus. He traced the history of how publishers were successful in legitimizing and protecting their commercial interests against those of academic freedom. From the beginning of the PKP in 1997, the PKP team discussed the freedom to read and to write, even when the term 'open access' had not yet been coined. He identified 3 tipping points for moving from the subscription model to open access and exhorted us to identify where we were on the open

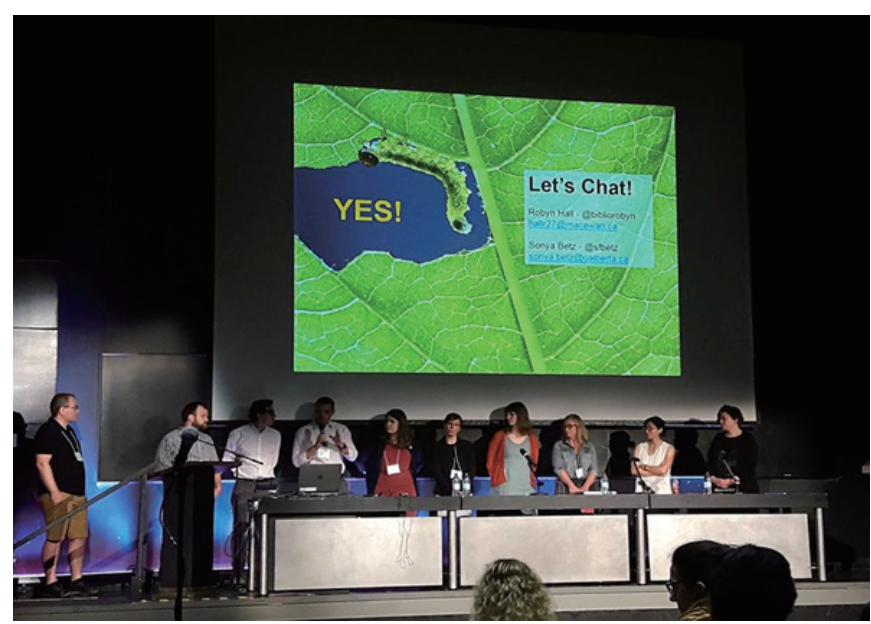

Fig. 2. Talks on library assisted scholarly publishing.

access quest. First, half of the recent literature is available online to researchers. The second point is that Elsevier has announced that they are the second largest open access publisher. Third, 5 publishers are now in possession of close to $50 \%$ of the published literature. He criticized the pervasiveness of commercial publishing models (including article processing charges to fund open access), the use of closed third-party systems and software, and the corporate concentration of scholarly publishing services. The power of community-based approaches in scholarly communication should be emphasized. He also drew our attention to students, who are novel players in scholarly publishing, at the conclusion of his address. His assertion that sharing research ideas and output through publication should not be limited to specific levels of academia, but should be open to anyone who is willing, at first seemed challenging given the fact that scholarly publishing is only led by academic societies and several research centers in South Korea. Throughout the speaker series over the last 2 days of the conference, more than 7 talks described publishing student journals or undergraduate journals supported by OJS and university libraries (Fig. 2). OJS as a platform for non-traditional scholarly output and open access publishing was discussed, and various use cases and experiences with it were shared. More on the technical issues and features of OJS and the results of the PKP Sprints were presented and discussed. In addition, viewpoints from the global South, including South Africa, Latin America and the crosscontinental project SciELO, were addressed. Issues regarding the sustainability and collaboration of non-commercial open access in Latin America are critical, as they are in Korea. Ina Smith from the Academy of Science of South Africa presented a summary of the rise of scholarly publishing in South Africa.

The conference provided attendees with valuable opportu- 
nities for networking. The PKP Sprints were group activities. The group members gathered together according to their own research interests and mingled with each other even after the group activity had concluded in order to have in-depth discussions. The Library Publishing Coalition meetup on August 3 provided an opportunity for attendees to learn about the Library Publishing Coalition, a community of academic libraries supporting a range of scholarly publishing practices. During the conference reception and Montreal dinner, attendees appreciated the French culture in Montreal and socialized before heading home.

By attending the PKP 2017 International Scholarly Publishing Conference, I had the opportunity to meet the global open access leader John Willinsky face-to-face. His speech on the copyright of the academic publications and the ownership of intellectual property from a historical perspective gave me much insight on scholarly publishing. Thoughtful opinions and comments were shared throughout the symposium, and even during the breaks and the casual social meet-ups. The government, societies, researchers, and publishers in Korea should meet and form a consensus regarding our open access quest in scholarly publishing.

As a systems developer and a community services manager, I became more informed about the workflow and the functions of the publishing platform used internationally through the technical session. The way that conference attendees interacted with each other using open web tools such as Slack and Google Drive in real time was quite impressive as well. This communication method seems efficient for eliciting hidden questions and opinions from all attendees, because offline meetings often tend to be led by just a few people.

The next conference will be held in 2 years in Canada. I hope that more researchers, editors, publishers, and librarians in Korea attend the next PKP conference and enjoy the opportunity to communicate with attendees who have common interests.

\section{Conflict of Interest}

No potential conflict of interest relevant to this article was reported.

\section{Acknowledgments}

This work was supported by a KISTI grant funded by the Korean government (K-18-L02-C01-S01).

\section{Reference}

1. Alperin JP, Stranack K, Garnett A. On the peripheries of scholarly infrastructure: a look at the journals using Open Journal Systems. Paper presented at: The 21st International Conference on Science and Technology Indicators; 2016 Sep 14-16; Valencia, Spain. 